\title{
Temporality of law in light of axiology
}

\author{
Denis S. Artamonov ${ }^{1, *}$, Stepan S. Kalinin ${ }^{2}$, Svetlana A. Kulikova ${ }^{3}$ and Sophia V. Tikhonova ${ }^{4,5}$ \\ ${ }^{1}$ Department of Theoretical and Social Philosophy, Saratov State University, 410012 Saratov, Russia \\ ${ }^{2}$ Scientific and Educational Center of Russian Language and Slavic Cultures, International Slavic Institute, 129085 Moscow, Russia \\ ${ }^{3}$ Department of Constitutional and Municipal Law, Saratov State University, 410012 Saratov, Russia \\ ${ }^{4}$ Department of Theoretical and Social Philosophy, Saratov State University, 410012 Saratov, Russia \\ ${ }^{5}$ Department of History of State and Law, Saratov State Law Academy, 410056 Saratov, Russia
}

\begin{abstract}
The main point of that article is to consider the axiological aspect of legal temporality. The presupposition of authors is consideration of the legal framework as a specific type of social frameworks. The social temporality theory is applicable for characterizing the temporal modes of social reality. The category of time is discussed as a phenomenon determined by events in terms of the social temporality theory. The authors regard the category of legal time as a special kind of social time. Legal time becomes reality through rules of law, legal events and juridical facts. They function as reference points that shed light on the temporal processes in law. The category of legal time is essential for characterizing the specifics of legal relationships that remain fixed in the past, present and future. The kinds of time are of direct importance to law. These mentioned kinds exist in three temporal dimensions that are absolutes. The law links people and their destiny with the past, regulates the rules of conduct in the present and determines social changes in the future as well as what happens to a person possibly. Thus, the value of time and temporality determines the value of law. Consideration of legal time in the axiological dimension gives us possibility to overview the role of temporal factors in the formation and development of legal relationships.
\end{abstract}

\section{Introduction}

An axiologically-oriented study of the temporality of law reveals the core foundations of the phenomenon of time and its importance for constructing the legal framework. Legal frameworks are embedded in the social framework. By this, a legal order is formed on the basis of the emergence of citizens' behavior that follows the law norms. A legal awareness can be considered as the most important factor of the development of social frameworks. Its foundation is the normative rule of law and order. The law norms and the legal awareness of persons at law elaborate a legal framework of a specific kind that is some subtype of social frameworks.

The legal framework can be regarded as the result of intersubjective reconsideration, construction, and interpretation of social reality. It can be explained in terms of its close interaction with the conscious activities of the law-makers, right enforcers and lawadministrators. Social reality gets some characterizing traits that make it possible to fix them as component parts of legal space. It is located in the legal environment. The social reality becomes comprehensible through legal concepts, legal norms and legal rules, persons at law and their interactions, legal relationships, legal duties, law-making, practices of law etc. Since the social reality is either accepted or rejected by social subject, it gets a correlation with the proper things [1]. Therefore, the axiological dimension is characterizing the legal framework, has a big importance to consider a social reality. The axiological part of the legal framework allows us to discuss the value matters of law as a form of public mind [2].

The existence of the legal framework as a particular form of social frameworks is based on its understanding as a social normative fact. It expresses two universal modes: they are the jurisprudence of gesture and the jurisprudence of text. The historical existence of the legal framework demonstrates us many variants of the system of justice. They formed the basis of the normative organization of social communication practices. The mentioned practices are actualized in terms of "acceptable and unacceptable" orders of relationship. Yu.A. Vedeneev states that "normativity is an ontological quality of social reality" [3]. Accordingly, social reality exists and evolves in space and time. The ontological quality of the legal framework is a legal norm. Any legal norm is a social phenomenon, which existence cannot be comprehended out of the bounds of space and time.

The legal framework is regarded as a special form of social frameworks in terms of social philosophy and philosophy of law. Within this framework, system of justice, rule of law and order are established with the help of the norms of law. The aim of establishing is to maintain social stability [4]. As a result, we should consider the temporality of law as a social category that correlates with the concept of social time.

\footnotetext{
Corresponding author: artamonovds@mail.ru
} 


\section{Research methods}

The methodological approach used in the present study is based on the post-classical paradigm. This paradigm focuses on the study of legal time in the broad historical and socio-cultural context. Consideration of the temporality of law presumes an interdisciplinary study of legal phenomena on the borders of philosophy and law theory in terms of the social-constructivist approach. It involves the study of legal reality as a result of subjective and intersubjective creative activity of a person.

\section{Results}

According to the theory of social time by P. Sorokin and R. Merton, the social time can be defined as a reflection of changes and movement of social phenomena in terms of other social phenomena [5]. Those phenomena could be taken as reference points. They are events that fill social time with meaning apprehended by human consciousness. Astronomical time, the measurement of time by clock, as well as the calendar subdivision of time give a set of abstract categories to any person. These categories are hardly perceived by humans. Otherwise, a category of time filled with social events forms the perceptual foundation of the temporality of being [6]. Social time is determined by periods of any valued social activity. The reference points are within their borders. Events that fascinate the public are marked as important ones for social life. Significations of time reflect the social life of a group. They are associated with social actions or achievements. Time is fixed in accordance with the rhythms of the public life. The homogeneity of social beatings, pulses and activities serves as a principle of umbrella. Each social group counts its time according to its behavior. Thus, social time can be considered as an ontological characteristic trait of social reality.

Legal time is a peculiar type of social time of special kind. As well, legal reality is a specific subcategory of social reality. Legal time conveys the beginning, duration and end of such things: any legal actions, norms, processes, states or events [7]. Legal time reflects the processes of legal control of people's behavior. It establishes certain limits and boundaries of legal relationship.

Legal relations are the most important and specific forms of social existence of law. They reveal and objectify the process of translating legal norms in public life. Legal ideals and legally-enforceable models of appropriate social behavior of people are actualized through legal relationship. A legal relationship can be considered as a connection between subjects. It is based on the interaction of the parties being actually enforced. This interaction is regulated by the norms of law. We could assume that legal relations are norms of law in action. Such consideration presupposes a temporal dimension of law.

The norms of law are rules of conduct of general effects. They get the form of imperative prescriptions and act as an instrument of control of social relations.
The norms of law being confirmed in laws and regulations got a temporal characteristic only in specific cases, when the time of their validity is fixed. The norm that acts as a source of legal relationship of law is always realized in time. The following properties of law norm are remarkable: duration, consistency, simultaneity, frequency, intensity, rhythmicality, continuity, discontinuity.

The norms of law are realized at some moment in time. We regard the concept of "moment of time" as follows: it is a reference point that represents the beginning or end of the interaction of legal persons, material bodies, states, events in some legal space. The duration of the law norms is the time length of the existence of legal relationship, legal events, phenomena, states. We denote a certain period that has passed from one time to another time, i.e. term. The development, change, termination of legal relationship and the corresponding legal consequences imply temporality [8]. It is reflected in the concept of a legal period. The legal period can be defined as time has got its own image in legal rules.

The temporality of law norms is actualized by the well-timed adoption of laws and regulations, their entry into legal force, duration of validity and duration of the legal period, clear regulation of legal relationship using reference time points, adherence to a certain sequence, as well as the obligation to fulfill the deadlines by legal persons [9].

The reference points of legal time are irrelative legal events. The law associates with them certain legal consequences are not related to human behavior. The natural phenomena are subject of discussion in that case: they are natural disasters, expiration of the term of limitation, attainment of legal age, natural death of a person, etc. Events such as death of a person or destruction of his property resulting from the effect of non-natural forces are relative legal events. They are consequences of human behavior (for example, murder, arson) caused by the actions of those people who are not participants of the forming legal relationship. We classify them as "relative" events because they do not cause legal relationship by themselves, but only their results [10]. Irrelative and relative legal events assume the time of their occurrence. They function as markers of legal temporality.

Events have time duration and they are independent from the will and consciousness of a person. They do not happen every moment. Due to this, the concept of event can be distinguished from the concept of instant [11]. Events are some disturbance; they are a borderline between the past and the future.

An event is considered as a jural fact in law. This fact entails legal consequences. The jural fact is confirmed in the assumption of the legal norm. It corresponds to certain life circumstances that make legal relationship and create legal consequences [12].

Legal relationships are regulated by means of time. They represent a peculiar form of social interaction of legal persons. It serves as a foundation of activities, the aim of them is to realize the legitimate interests of citizens [13]. Legal persons seek to satisfy their interests, 
act in time and realize the concept of time through both legal events and juridical facts. Thus, legal time is considered as the beginning, duration and termination of any legal effects based on the norms of law with a temporal dimension.

The persons of law-making are guided by the temporal legal norms that establish the ways of validity of normative legal acts. These persons create such means; public authorities use to control the behavior of citizens and tools of regulation of social processes.

These temporal and spatial relations are specific traits of laws and regulations of various law branches. Our next point is to explore some distinctive features of the constitutional texts of different states. These features are appropriate for the text mentioned above.

The adoption of the constitution is most often due to a sharp shift in social interactions that occurs as a result of revolution, reforms, the victory of liberation movements, and the struggle for national independence. The mentioned historical events could be regarded as preliminary stages of the constitutional development, since their effects must be documented and reconsidered by means of a political and legal act that has the legal supremacy. We define such type of legal acts as a constitution. The specific character of the constitution is in determining the basic principles of the state system and the nature of relations between state, society and human being. The foundations of the national legal system as well as spiritual and moral guidelines for the development of society are provided by constitution [14]. The unique nature of the constitution determines the temporal architectonics of the constitutional text. The text of constitution expands into two time dimensions: the dimension of the present time and the dimension of the eternity.

Let's begin from the temporal dimension of the present. In such case, the reference point of the constitution is the moment of its adoption, which is directly expressed in the enacting clauses of the constitutional text. The adoption of the constitution is regarded as the high point of the state's life as well as the central event of the constitutional text. The enacting clauses (preambles) of many working constitutions contain the key phrase "the constitution is adopted/we adopt the constitution". After that, the prerequisites, goals and fundamental values are described. The basic law of the state is intended on them. Among the fundamental rules it could be found the changes in the government system and government form, the establishment of new principles of state construction, the transformation of the system of social relationship as well as adjustment to the modern community of nations etc. The constitution can be considered as a political and legal act of the present time in that sense. It preserves the system of values and the imagination of most preferable system of government. This set of conceptions is elaborated by certain social-political group that has got into power at a certain point in historical time.

Commonly, the change procedure of constitution has a grade of complexity than "ordinary" statutory law. Therefore, over time the constitution transforms into a written monument of its historical age. This written artifact embodies constitutional expectations and fears that the negative historical experience of the past historical period in state's life might repeat. In this sense, the Constitution of the French Republic, The Constitution of the United States of America and the constitutions of some other states are bright examples. Their original texts remain unchanged and they are valid. Then, articles, chapters, parts, inspired by their time and aimed to solve completely different problems, are added to the original texts subsequently [15]. This structure of the constitutional text is similar to archaeological tandem levels. Each part of the working constitution is an artifact of the constitutional and legal development of the country. On the other hand, it preserves integrity and continuity of such development.

The constitutions are unique documents because, unlike other legal acts, the texts of them usually contain sections providing for the procedure of changes in the constitution and the procedure of adoption of a new constitution. It implies that the current present state may find its end. However, reference points are not marked that would determine time and conditions of working constitutional bound (and the terms of their validity) and the corresponding time and conditions of adoption of a new one. This exploration could be considered as a common rule.

The abolition of a former constitution and the adoption of a new constitution are processes of documenting the value gap between the generations that created the previous and subsequent constitutions. It is regarded as a change of the social axiological paradigm. This event seems to be dramatic for society. It has catastrophic character for the constitutional text, since this text loses all its main functions and ceases to be the basic law of the state.

The present things are correlated in constitutional texts with the eternity or with such things that exist for a very long historical period in almost cases. These periods exceed the periods of human life significantly, therefore, they could be perceived as non-temporal units. The dimension of the eternity is expressed in the constitutional text by the fact that the reference points are landmarks of distant past and uncertain future. The past is represented through the mention of ancient historical events and the memory of the ancestors' deeds. The future is defined in terms of horizon of social, economic, spiritual and ethic aims and scopes that are object of striving. The teleology of the future makes its temporality uncertain.

The typical situation is that many constitutions have remarks of its adoption by the whole people. It is emphasized on the term "people", not on the masses of citizens who are eligible to vote at a particular time and are getting ready to vote in a constitutional referendum. The concept of "people" and "nation" unites both ethnic and confessional communities that share a common historical destiny. Also, these concepts refer to the past and future generations, compatriots living abroad who continue to pay respect for national cultural traditions. In addition, the constitution is adopted for the greater public good. Thus, it needs to have regard both to the ethnic mentality and to the spiritual and moral values 
that have evolved over the centuries. The temporal aspect of the eternity is also actualized in such facts that constitutions may contain references to metaphysical subjects (God, for example), some sacred texts (The Bible; The Quran), some metaphysical concepts (humanity; eternal human values; natural law, determined by the human nature).

Thus, the remarkable typological trait of constitutional text is an inherent feature of a temporal conflict between the present time and the eternity. The temporal conflict of constitutional text is basically controversial. As a technical legal matter, it may be proposed its partial resolution by amendments of constitution and changes in the constitutions. However, its essential development is the key to the movement of the state and public institutions towards an ideal model that exists in a non-temporal dimension.

\section{Discussion}

Time is considered in terms of legal science as a set of rules for the application of regulatory legal acts. It includes the time of enactment, the manner for the enactment and limits of operation of law in time. Law time management mechanisms include operations with the present, past and future. The foundation of law is the past. Due to this, the law is associated with historical time that could be determined through the characteristics of the periods of social community development. Law seems to be examined as a kind of memory that turns the memory of a legal event into a legal norm. When the norms of habits were transformed into laws the law was a kind of representation of the past facts that refer to legal relationships from the moment of law emergence. The law exists in the present time that is considered as the period of time, the enforced legal norms are valid. Although the future represents the field of probabilistic functioning of legal norms, legal events and legal facts, it got a definition in terms of statutory and regulation acts. A significant part of them is aimed at anticipation (or planning for every legal event) [16]. The law does not document what is happening at the present moment, but what is going to happen. The law-makers in the present time regulate what should happen in the future. They perform it in a way that the legal relationship that could arise would already be documented and defined upon the occurrence of provided legal events after a certain period of time [17].

Temporality is integral to the law. The principle of temporal correlation provides legal implications when a legal relationship is created. Temporality is not a change agent of events that occur over time by its own. It contributes to the identification of cause and effect relationship [18].

The law takes part in the formation of the future, but it can also give rise to any future legal position. The law is capable of making the past actual or transmitting it to the present time. Thus, the foundation of law is the reality of time that makes it the support of any human activity. The law is inextricably linked with the category of time. The initial point of law is the moment or duration of any legal position enshrined by a rule of law. Thus, the main component of legal time considered in the theory of law is the process of persistent changes in legal reality. The previous legal relationships disappear and the new norms of law arise, as well as legal acts that shape the development of legal science and legal practice.

\section{Conclusion}

Legal norms can be considered as an attempt to stabilize social interactions. Since they are in continuous formation, the legal order becomes a challenge of the time. It is aimed at preserving the social order that is affirmed and consolidated by legal order. The law is constantly adapting to the situation in order to work in the terms of social transformations. Moreover, it can lead this transformation or serve as a tool for the rising of a new social order. That is, the law serves as a source of socio-historical changes or a source of their antecedence. The law remains the conventional and habitual things in the common life fixed, but it also builds up reasons for the emergence of innovations and determines the possibility of putting these innovations into practice.

Legal phenomena operate with time. They grow and disappear at a certain time, conditioned by reality. They exist for a certain period of time and control the temporal processes taking place in social frameworks. The definition of a legal phenomenon in time is qualified by legal framework through the balance of the past, present and future layers of time. Consideration of law in time is always valuable both for social cognition and legal cognition, as it gives the possibility to explore and estimate the causality of legal events.

Time and law are fundamentals of humanities knowledge that form the basis for understanding social interactions. Time and law are the phenomena of equal level in the social sphere and in the sphere of normativity and are quite comparable in their importance. They are absolute values, and the quantity of these values entails. The operation of law is associated with the operation of time. This fact presupposes the predictive function of law, suggesting a set of possible variations of behavior that it conducts.

Time is a substantial component of law. It provides some possibilities to document the past, to regulate the present and to anticipate the future. The temporal elements of the social structure maintained by system of law actually protect the interests of people. Time connects people with the past, and it affords them the acceleration in the present. Consequently, it allows them to feel confident about the future. That is why, time in law is of fundamentals for any person. The source of law is the moral norms of the human society. The law reflects the structure of society and some social challenges being influenced by multi-item factors. The law develops over time functioning as a mean of serving the social needs. Thus, the valuableness of law is intermediated by the valuableness of time. 
The reported study was funded by RFBR, project number 20011-00297 «Time mythologization in the modern media environment: the risks of transformation, construction strategies, discursive practices».

\section{References}

1. K. McNeilly, Are Rights Out of Time? International Human Rights Law, Temporality, and Radical Social Change. Social \& Legal Studies, 28, (2018). 096466391881572.

DOI: $10.1177 / 0964663918815729$.

2. B.-B. Keebet von, Trust and the temporalities of law, The Journal of Legal Pluralism and Unofficial Law, 46(1), 1-17, (2014). 10.1080/07329113.2014.894743

3. Yu. A. Vedeneev, Legal reality: ontology and epistemology, Lex russica (Russian law), 102(5), 722 (2015).

4. E. Grabham, E. Cunliffe, S. Douglas, S. Keenan, R. Mawani, A. M'charek, Exploring Relationships between Time, Law and Social Ordering: A Curated Conversation, 8(2) (2018).

5. P.A. Sorokin, R.K. Merton, Social time: the experience of the methodological and functional analysis, Sociological Studies. Socis, 6, 112-119 (2004).

6. A. Crawford, Temporality in restorative justice: On time, timing and time-consciousness, Theoretical Criminology, 19(4), 470-490 (2015). DOI: https://doi.org/10.1177/1362480615575804

7. T. L. Tenilova, Space and time in the legal life of society: correlation of categories, Legal science and practice: Bulletin of the Nizhny Novgorod Academy of the Ministry of Internal Affairs of Russia, 2(13), 105-110 (2010).

8. S. V. Malikov, Conceptual foundations of the temporality of criminal law testing, Actual problems of Russian law, 9(70), 108-115 (2016). DOI: 10.17803/1994-1471.2016.70.9.108-115.

9. T. Chowdhury, Time Frames and Legal Indeterminacy, Canadian Journal of Law \& Jurisprudence, 30(1), 57-76 (2017). doi:10.1017/cjlj.2017.3

10. R. Mawani, Law As Temporality: Colonial Politics and Indian Settlers, UC Irvine Law Review, 4, 1 (2014)

11. R. Mawani, The Times of Law. Law \& Social Inquiry, 40(1), 253-263 (2015). doi:10.1111/1si.12117

12. T.Z. Chowdhury, Temporality and Criminal Law Adjudication's Multiple Pasts, Liverpool Law Rev, 38, 187-206 (2017). https://doi.org/10.1007/s10991-017-9192-8

13. A. Khoday, Every Moment Counts: The Legal Value of Time in Canadian Criminal Law and Procedure (2021), Criminal Law Quarterly, 63 (2021). Retrieved from: https://ssrn.com/abstract=3841761

14. A. Wistrich, The evolving temporality of law making, Connecticut Law Review, 44(3), 737 (2012)

15. J. Crowe, C.Y. Lee, Law as Memory. Law Critique, 26, 251-266 (2015). DOI: https://doi.org/10.1007/s10978-015-9162-z

16. E. G. Voide, The time factor and human rights: the temporal aspect of legal reality, Space and Time, 1(7), 93-98 (2012)

17. L. Farmer, Time and Space in Criminal Law, New Criminal Law Review 1, 13(2), 333-356 (2010). DOI: https://doi.org/10.1525/nclr.2010.13.2.333

18. A. Khan, Temporality of Law, McGeorge Law Review, 40 (2008). Retrieved from: https://ssrn.com/abstract=1271262 